American Journal of Applied Sciences 7 (6): 756-762, 2010

ISSN 1546-9239

(C) 2010Science Publications

\title{
Homogeneous Bubbles during Jet Impingement Quenching
}

\author{
M.A. Islam and S.F. Ahmed \\ Department of Mechanical Engineering, \\ Bangladesh University of Engineering and Technology, Dhaka-1000, Bangladesh
}

\begin{abstract}
Problem statement: Jet impingement quenching has a very effective and large cooling potential and is a very effective means of cooling for many applications. It gives rise to heterogeneous and/or homogeneous nucleation of bubbles, which is yet to be explored. Approach: Analytically investigate the phenomenon that happened during a brief contact of a water jet impinging on a hot surface. In particular, explore the possibility of homogeneous bubble formation during jet impingement quenching. A simple semi-infinite conduction heat transfer model was considered in this case and the heat transfer analysis had been carried out for two heating cases of the impinging liquid, namely with (i) Prescribed Surface Temperature (PST-case) and (ii) Time-dependent Surface Temperature (TST-case). For each of above cases, explicit equations for temperature distribution within liquid, average liquid temperature, average internal energy and surface heat flux had been derived as a function of liquid depth and contact time. These equations were solved numerically and their outcomes were discussed. Furthermore, a critical contact time, $\mathrm{t}^{*}$ at which the temperature on the opposite side of the liquid depth reached saturation temperature, $\mathrm{T}_{\text {sat }}$ was determined. The heat flux $\left(\mathrm{q}_{\mathrm{s}}\right)$ at time $\mathrm{t}^{*}$ was also determined and compared with the thermodynamic limit of the maximum heat flux $\left(\mathrm{q}_{\max }\right)$ which decided the validity of this analytical investigation. Results: During jet impingement quenching of hot surfaces near/above the thermodynamic limiting temperature, water stored enough energy for a contact period of 5-10 $\mu$ s depending on the type of boundary conditions considered for triggering homogeneous bubble nucleation. A contact time of $4 \mu \mathrm{s}$ was required to trigger homogeneous bubble nucleation for the conditions where the impinging surface had a fixed temperature throughout the cooling process. A contact time of $6.5 \mu \mathrm{s}$ was required to initiate homogeneous bubble nucleation for the conditions where the impinging surface temperature dropped at a rate depending on time. For both cases, the average internal energy of the liquid exceeded the minimum energy necessary for bubble formation. Moreover, the average heat flux, q never exceeded the thermodynamic limit of the maximum heat flux, $\mathrm{q}_{\max }$. Conclusion: When water was heated above the thermodynamic limit of superheat during jet impingement, there is always a chance of homogeneous bubble nucleation.
\end{abstract}

Key words: Homogeneous nucleation of bubbles, heat conduction, jet impingement quenching, semiinfinite solid, thermodynamic limit of liquid superheat

\section{INTRODUCTION}

Jet impingement quenching has a very effective and large cooling potential and is a very effective means of cooling for many applications. It is very important in Loss Of Coolant Accident (LOCA) analysis, steel manufacturing, metallurgy, microelectronic devices and thermal management processes. It may be useful in elucidating poorly understood phenomena such as Leidenfrost phenomenon and homogeneous nucleation. A comprehensive review of jet impingement boiling was made by Wolf et al. (1993). They observed that in contrast to research on nucleate boiling and critical heat flux, there is a scarcity of concrete studies relating to jet impingement for the film boiling and transition regimes.

Jet impingement cooling of a hot surface may give rise to heterogeneous and/or homogeneous nucleation of bubbles, which is yet to be explored. A number of interesting phenomena have been reported for jet impingement quenching. Piggott et al. (1976) reported a delay to the movement of the wetting front during quenching heated rods from an initial temperature of

Corresponding Author: M.A. Islam, Department of Mechanical Engineering,

Bangladesh University of Engineering and Technology, Dhaka-1000, Bangladesh 
$700^{\circ} \mathrm{C}$ with a sub-cooled water jet. The quench began with quiet film boiling and then a white patch around $5 \mathrm{~mm}$ in diameter appeared beneath the jet. The liquid film then broke into tiny droplets in a spray pattern, which was followed by an oscillating liquid sheet that lifted from the surface of the rod. Finally the wetting front moved forward over the heated surface. Some recent works include Hammad et al. (2004); Woodfield et al. (2005); Mozumder et al. (2005) and Islam et al. (2006a; 2006b). Most of these recent studies have been performed by quenching a cylindrical block of initial temperatures ranging from $250-400^{\circ} \mathrm{C}$. These studies included flow visualization, surface temperature, surface heat flux, cooling curves, boiling curves, resident time (wetting delay) and boiling sound. Islam et al. (2007a) reported some excellent video images at early stages of jet impingement quenching (Fig. 1 is an example of such images) and demonstrated a clue towards development of a model of heat transfer. Therefore, the nature of the phase change phenomena and characteristics of heat transfer for impinging jets at early stages in the high temperature context is yet to be understood clearly. Most recently, Islam et al. (2007b) estimated the average amount of energy stored in the superheated liquid $\left(\mathrm{U}_{\text {avg }}\right)$ and compared it with the minimum energy $\left(\mathrm{W}_{\mathrm{cr}}\right)$ which must be supplied to form a bubble cluster in order to find the possibility of homogeneous bubble nucleation during jet impingement quenching.

As a follow up of the study by Islam et al. (2007b), the present analysis finds the average surface heat flux $\left(\mathrm{q}_{\mathrm{s}}\right)$ during jet impingement quenching at the early stages using a new approach by the concept of critical time $\mathrm{t}^{*}$ and compares it with the maximum thermodynamic limit of surface heat flux $\left(q_{\max }\right)$ determined from molecular dynamics. This comparison assures the validity of the analytical study as well as the information of the average amount of stored energy and the minimum energy required for bubble formation gives the possibility of homogeneous bubble nucleation during jet impingement quenching. The analysis methodology is explained under the discussions on the mathematical model after which results of calculated variables are discussed clearly.

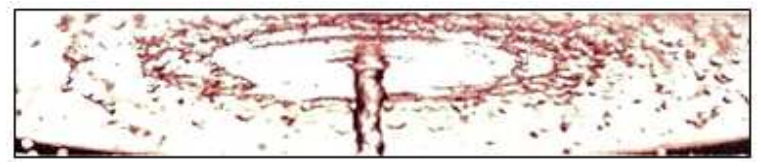

Fig. 1: A video image $30 \mathrm{~ms}$ after jet impingement during jet impingement cooling

\section{MATERIALS AND METHODS}

Model: Liquid in brief contact with the hot solid during jet impingement quenching can be considered as one dimensional semi-infinite solid through which heat from the hot solid is conducted (Fig. 2). Therefore, a simple conduction analysis can find the temperature distribution within the liquid. The temperature distribution is dependent on the jet temperature, the interface temperature, the thermal diffusivity of both liquid and solid, the depth of liquid from the solid surface and the time of brief contact.

The governing equation of the model is given by:

$\frac{\partial^{2} \mathrm{~T}}{\partial \mathrm{x}^{2}}=\frac{1}{\mathrm{a}} \frac{\partial \mathrm{T}}{\partial \mathrm{t}}$ for $0<\mathrm{x}<\infty$

The boundary condition at $\mathrm{x}=0$ can be either of the following types:

- $\quad$ Prescribe Surface Temperature (PST): $\mathrm{T}=\mathrm{T}_{\mathrm{i}}$

- Time dependent Surface Temperature (TST): $\mathrm{T}=\mathrm{kt}$

The initial condition:

$$
\mathrm{T}=\mathrm{T}_{1} \quad \text { for } 0<\mathrm{x}<\infty
$$

Where:

$\mathrm{T}_{1}=$ The jet temperature

$\mathrm{T}_{\mathrm{i}}=$ The interface temperature

$\mathrm{a}=$ The thermal diffusivity of liquid

$\mathrm{k}=\mathrm{A}$ constant representing the rate of change in surface temperature

$\mathrm{x}=$ The depth of liquid from the solid surface

$\mathrm{t}=$ The time elapsed after jet comes in contact with the surface

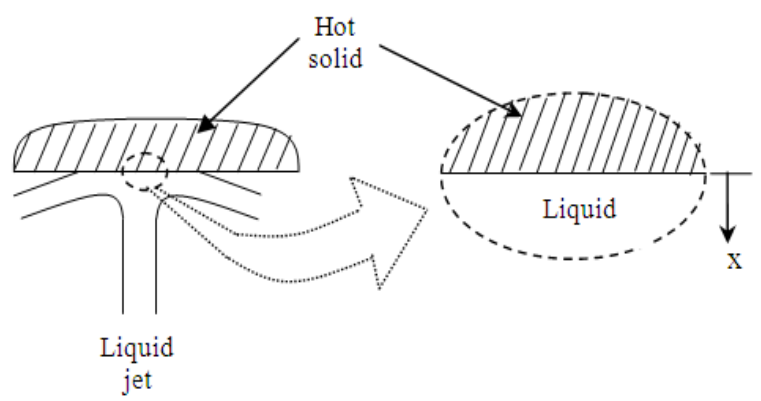

Fig. 2: Jet impingement quenching and semi-infinite liquid 
The interface temperature, $T_{i}$ mentioned above is calculated according to Carslaw and Jaeger (2001) using Eq. 2 as:

$$
\frac{\mathrm{T}_{\mathrm{s}}-\mathrm{T}_{\mathrm{i}}}{\mathrm{T}_{\mathrm{i}}-\mathrm{T}_{1}}=\sqrt{\frac{(\rho c \lambda)_{1}}{(\rho c \lambda)_{\mathrm{s}}}}
$$

Where:

$\mathrm{T}_{\mathrm{s}} \quad=$ The surface temperature of solid

' $\rho$ ', 'c', ' $\lambda$ ' = Respectively, the density, specific heat and thermal conductivity and the subscripts

' 1 ' and 's' = Stand for liquid and solid respectively

Depending on boundary conditions two different cases are described below.

Prescribed Surface Temperature (PST) case: The temperature distribution within the liquid for this case is given by:

$$
\mathrm{T}(\mathrm{x}, \mathrm{t})=\mathrm{T}_{1}+\left(\mathrm{T}_{\mathrm{i}}-\mathrm{T}_{1}\right) \operatorname{erfc}(\mathrm{x} / \sqrt{4 \mathrm{at}})
$$

The amount of energy stored in the superheated liquid with reference to saturated liquid is:

$$
\mathrm{u}(\mathrm{x}, \mathrm{t})=\mathrm{c}\left(\mathrm{T}(\mathrm{x}, \mathrm{t})-\mathrm{T}_{0}\right)
$$

Where:

$\mathrm{c}=$ The specific heat of the liquid

$\mathrm{T}_{0}=$ The reference temperature, which can reasonably be the saturation temperature at ambient pressure

The average of the stored energy over the depth of the liquid is:

$$
\bar{u}\left(x_{e}, t\right)=\frac{1}{x_{e}} \int_{0}^{x_{e}} u(x, t) d x
$$

where, $x_{e}$ is the liquid depth equal to the diameter of the critical vapor embryo in the superheated liquid. The value of $x_{e}\left(=2 r_{e}\right)$ is not known. It depends on the liquid temperature which in turn depends on the contact time t. The equilibrium embryo size is given by Eq. 6 according to Carey (1992):

$$
r_{e}=\frac{2 \sigma}{P_{s a t}(\bar{T}) \exp \left[v_{1}\left\{P_{\propto}-P_{s a t}(\bar{T})\right\} / R \bar{T}\right]-P_{\propto}}
$$

Equation 5 can be simplified as follows:

$$
\overline{\mathrm{u}}\left(\mathrm{x}_{\mathrm{e}}, \mathrm{t}\right)=\mathrm{c}\left(\mathrm{T}_{1}-\mathrm{T}_{0}\right)+\frac{\mathrm{c}\left(\mathrm{T}_{\mathrm{i}}-\mathrm{T}_{1}\right)}{\left(\mathrm{x}_{\mathrm{e}} / \sqrt{4 \mathrm{at}}\right)}\left(\frac{1}{\sqrt{\pi}}-\operatorname{ierfc}\left(\mathrm{x}_{\mathrm{e}} / \sqrt{4 \mathrm{at})}\right)\right.
$$

Here:

$\operatorname{ierfc}\left(x_{e} / \sqrt{4 a t}\right)=\frac{1}{\sqrt{\pi}} \exp \left(-x_{e}^{2} / 4 a t\right)-\frac{x_{e}}{\sqrt{4 a t}} \operatorname{erfc}\left(x_{e} / \sqrt{4 a t}\right)$

In order to get an estimate of $x_{e}$, the average temperature of the liquid over a certain volume of the liquid in contact is considered as given in the following equation:

$\bar{T}\left(x_{e}, t\right)=\frac{1}{x_{e}} \int_{0}^{x_{e}} T(x, t) d x$

Equation 8 can be manipulated analytically to have a simplified shape as follows:

$$
\overline{\mathrm{T}}\left(\mathrm{x}_{\mathrm{e}}, \mathrm{t}\right)=\mathrm{T}_{1}+\left(\mathrm{T}_{\mathrm{i}}-\mathrm{T}_{1}\right) \frac{\sqrt{4 \mathrm{at}}}{\mathrm{x}_{\mathrm{e}}}\left(\frac{1}{\sqrt{\pi}}-\operatorname{ierfc}\left(\mathrm{x}_{\mathrm{e}} / \sqrt{4 \mathrm{at})}\right)\right.
$$

Equation 7 can be simplified using average liquid temperature as follows:

$$
\overline{\mathrm{u}}\left(\mathrm{x}_{\mathrm{e}}, \mathrm{t}\right)=\mathrm{c}\left(\overline{\mathrm{T}}\left(\mathrm{x}_{\mathrm{e}}, \mathrm{t}\right)-\mathrm{T}_{0}\right)
$$

Time dependant Surface Temperature (TST) case: The temperature distribution within the liquid for this case is given by:

$T(x, t)=T_{1}+4 k t i^{2} \operatorname{erfc}(x / \sqrt{4 a t})$

Where:

$\mathrm{i}^{2} \operatorname{erfc}\left(\mathrm{x} / \sqrt{4 \mathrm{at})}=\frac{1}{4}[\operatorname{erfc}(\mathrm{x} / \sqrt{4 \mathrm{at}})-2 \operatorname{xierfc}(\mathrm{x} / \sqrt{4 \mathrm{at}})]\right.$

The average temperature distribution has the following simplified form:

$$
\overline{\mathrm{T}}\left(\mathrm{x}_{\mathrm{e}}, \mathrm{t}\right)=\mathrm{T}_{1}+\frac{\mathrm{kt}}{\left(\mathrm{x}_{\mathrm{e}} / \sqrt{4 \mathrm{at}}\right)}\left(\frac{2}{3 \sqrt{\pi}}-4 \mathrm{i}^{3} \operatorname{erfc}\left(\mathrm{x}_{\mathrm{e}} / \sqrt{4 \mathrm{at}}\right)\right)
$$

Where:

$$
\mathrm{i}^{3} \operatorname{erfc}\left(\mathrm{x}_{\mathrm{e}} / \sqrt{4 \mathrm{at})}=\frac{1}{6}\left[\begin{array}{l}
\operatorname{ierfc}\left(\mathrm{x}_{\mathrm{e}} / \sqrt{4 a t}\right)- \\
2 \mathrm{x}_{\mathrm{e}} \mathrm{i}^{2} \operatorname{erfc}\left(\mathrm{x}_{\mathrm{e}} / \sqrt{4 a t}\right)
\end{array}\right]\right.
$$


The average of the stored energy can be calculated by Eq. 10 as before.

Average and maximum heat flux: The Average Heat Flux can be derived by integrating the heat flux over a time duration $\mathrm{t}^{*}$ :

$\overline{\mathrm{q}}_{\mathrm{s}}=-\left(\mathrm{T}_{\mathrm{s}}-\mathrm{T}_{1}\right) \frac{\sqrt{(\rho c \lambda)_{1}}}{1+\sqrt{(\rho c \lambda)_{1} /(\rho \mathrm{c} \lambda)_{\mathrm{s}}}} \frac{1}{\sqrt{\mathrm{t}^{*}}}$

The thermodynamic limit of maximum heat flux can be determined from molecular dynamics by:

$q_{\max }=\rho_{g} h_{f g} \sqrt{\frac{R T}{(2 \pi M)}}$

Minimum required energy: The net energy $W_{c r}$, which must be deposited to form the bubble cluster is given by:

$\mathrm{W}_{\mathrm{cr}}=\frac{4}{3} \pi \mathrm{r}_{\mathrm{e}}^{2} \sigma$

Critical time $\mathbf{t}^{*}$ : This is the time at which the temperature on the opposite $\mathrm{x}=\mathrm{x}_{\mathrm{e}}$ of the cluster reaches saturation temperature $\mathrm{T}_{\text {sat }}$, i.e.:

$\mathrm{T}\left(\mathrm{x}_{\mathrm{e}}, \mathrm{t}^{*}\right)=\mathrm{T}_{\mathrm{sat}}$

According to the definition of critical time, we get the following equation for the PST case:

$\mathrm{T}_{1}+\left(\mathrm{T}_{\mathrm{i}}-\mathrm{T}_{1}\right) \operatorname{erfc}\left(\frac{\mathrm{x}_{\mathrm{e}}}{\sqrt{4 \mathrm{at}^{*}}}\right)=\mathrm{T}_{\mathrm{sat}}$

which can be rearranged as follows:

$\operatorname{erf}\left(\frac{\mathrm{x}_{\mathrm{e}}}{\sqrt{4 \mathrm{at}^{*}}}\right)=\frac{\mathrm{T}_{\mathrm{i}}-\mathrm{T}_{\mathrm{sat}}}{\mathrm{T}_{\mathrm{i}}-\mathrm{T}_{1}}$

Therefore, the value of $\mathrm{t}^{*}$ for the PST case can be calculated by Eq. 18 using iteration procedure.

Again for TST case, applying the condition for critical time, we get:

$\mathrm{T}_{1}+4 \mathrm{kt} \mathrm{i}^{2} \operatorname{erfc}\left(\frac{\mathrm{x}_{\mathrm{e}}}{\sqrt{4 \mathrm{at}^{*}}}\right)=\mathrm{T}_{\text {sat }}$

which is simplified to: $\mathrm{t}^{*}\left[\operatorname{erfc}\left(\frac{\mathrm{x}_{\mathrm{e}}}{\sqrt{4 \mathrm{at}^{*}}}\right)-\frac{2 \mathrm{x}_{\mathrm{e}}}{\sqrt{\pi}} \exp \left(\frac{-\mathrm{x}_{\mathrm{e}}{ }^{2}}{4 \mathrm{at}^{*}}\right)\right.$

$\left.+\frac{2 \mathrm{x}_{\mathrm{e}}{ }^{2}}{\sqrt{4 \mathrm{at}^{*}}} \operatorname{erfc}\left(\frac{\mathrm{x}_{\mathrm{e}}}{\sqrt{4 \mathrm{at}^{*}}}\right)\right]=\frac{\mathrm{T}_{\text {sat }}-\mathrm{T}_{1}}{\mathrm{k}}$

Therefore, the value of $\mathrm{t}^{*}$ is calculated by Eq. 20 using iteration procedure.

Solution procedure: Following steps are followed to calculate $\mathrm{T}_{\text {lavg }}, \mathrm{U}_{\text {avg, }} \mathrm{q}_{\mathrm{s}}$ and $\mathrm{q}_{\max }$ using the value of $\mathrm{k}$ is taken as $37.7 \times 10^{6} \mathrm{~K} \mathrm{sec}-1$, from Iida et al. (1994):

1. For any time $\mathrm{t}$, an initial guess is made for $\mathrm{x}_{\mathrm{e}}$.

2. Properties are taken at $100^{\circ} \mathrm{C}$

3. Value of $x_{\mathrm{e}}$ is stored as $\mathrm{x}_{\text {eold }}$

4. Using Eq. 8, $\mathrm{T}_{\text {lavg }}$ is calculated and properties are again taken at $\mathrm{T}_{\text {lavg }}$

5. Using Eq. 6, the value of $\mathrm{r}_{\mathrm{e}}$ is computed and then $\mathrm{x}_{\mathrm{e}}$ is taken to be $2 r_{e}$

6. The critical time $\mathrm{t}^{*}$ is calculated using Eq. 16 and the heat flux $\mathrm{q}_{\mathrm{s}}$ at time $\mathrm{t}^{*}$ is calculated from Eq. 13

7. The maximum heat flux $\mathrm{q}_{\max }$ and minimum required energy $\mathrm{W}_{\mathrm{cr}}$ are calculated using Eq. 14 and 15 respectively.

8. Step (3) is repeated until absolute value of $\left(\mathrm{x}_{\mathrm{e}^{-}}\right.$ $\left.\mathrm{x}_{\text {eold }}\right) / \mathrm{x}_{\text {eold }}$ is less than 0.0001

9. $\mathrm{U}_{\mathrm{avg}}$ is calculated using Eq. 10

10. The values of $\mathrm{t}, \mathrm{t}^{*}, \mathrm{r}_{\mathrm{e}}, \mathrm{x}_{\mathrm{e}}, \mathrm{T}_{\text {lavg }}, \mathrm{U}_{\mathrm{avg}}$ and $\mathrm{W}_{\mathrm{cr}}$ are recorded

11. The values of $q$ and $q_{\max }$ are compared, whether $q$ is greater than $\mathrm{q}_{\max }$

12. The value of time is incremented and then Step (211) are repeated

The flow chart of the algorithm is shown in Fig. 9.

\section{RESULTS}

The temperature of the liquid impinging on the hot surface has been taken as $50^{\circ} \mathrm{C}$ in making comparison among different cases.

Figure 3 shows the effect of contact time, $t$ on variation of liquid temperature with liquid depth, $\mathrm{x}$ for TST case. The liquid initial temperature is $50^{\circ} \mathrm{C}$. At the surface $(x=0 \mathrm{~nm})$, water has the same temperature for all values of contact time. As contact time increases, water temperature increases over the water depth shown (0-250 nm) and assumes different values for different contact times.

Figure 4 shows the variation of $T_{\text {lavg }}$ and $r_{e}$ with time for two different cases. As $\mathrm{T}_{\text {lavg }}$ increases, the pressure inside the liquid increases and hence the critical radius of the bubble $r_{e}$ decreases which can clearly be observed from the graph. For PST case, $\mathrm{T}_{\text {lavg }}$ is above $300^{\circ} \mathrm{C}$ for the contact times in the range from 4-8.5 $\mu \mathrm{s}$. 
Am. J. Applied Sci., 7 (6): 756-762, 2010

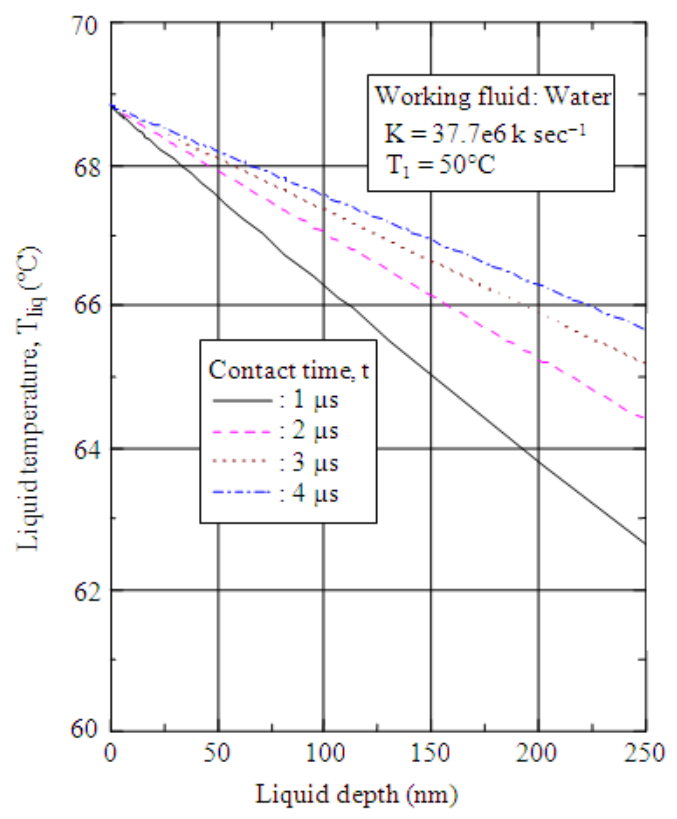

Fig. 3: Effect of contact time on the temperature distribution for TST case

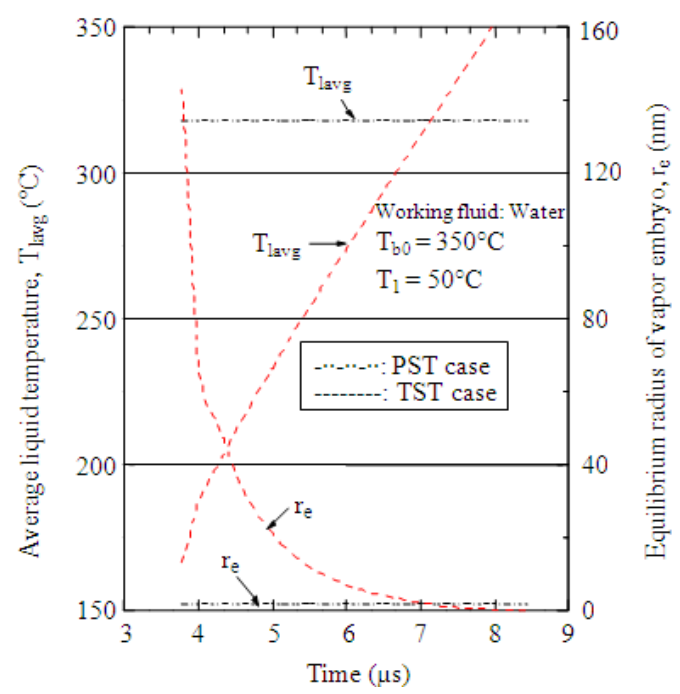

Fig. 4: Variation of average liquid temperature and equilibrium radius with contact time for different cases

For TST case, the value of $\mathrm{T}_{\text {lavg }}$ exceeds $300^{\circ} \mathrm{C}$ for contact time of $7 \mu \mathrm{s}$. The rate of change in $\mathrm{T}_{\text {lavg }}$ is much higher for TST case than that for PST case. For PST case, steady and converged solution for $r_{e}$ is achieved within about $4 \mu \mathrm{s}$. For TST case, although solutions are found after $5 \mu \mathrm{s}$, the value of $r_{e}$ varies subsequently in the time range shown.

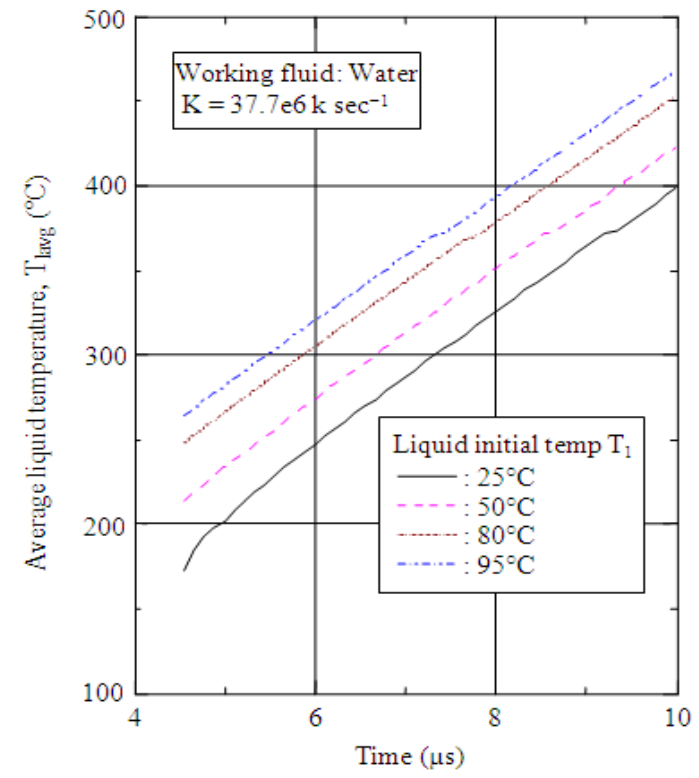

Fig. 5: Effect of jet initial temperature on average liquid temperature for TST case

Figure 5 shows the effect of liquid initial temperature, $\mathrm{T}_{1}$ on variation of average liquid temperature, $\mathrm{T}_{\text {lavg }}$ with time, $\mathrm{t}$ for TST case. As $\mathrm{T}_{1}$ increases, $\mathrm{T}_{\text {lavg }} \mathrm{Vs} \mathrm{t}$ curve shifts to the left which indicates that for a fixed value of $t, T_{\text {lavg }}$ increases with $T_{1}$. The higher the value of $T_{1}$, the sooner water will reach homogeneous limit of $300^{\circ} \mathrm{C}$. The stability of the bubbles of critical radius thus depends on the value of jet temperature $T_{1}$. Similar effects of $T_{1}$ has been observed for PST case.

Figure 6 shows the effect of liquid initial temperature, $T_{1}$ on the variation of equilibrium radius of vapor embryo, $r_{e}$ with time, $t$ for TST case. It is found that $r_{e}$ reaches a stable value more quickly for higher values of $T_{1}$.

Figure 7 shows the variation of $\mathrm{U}_{\text {avg }}, \mathrm{W}_{\mathrm{cr}}$ and $\mathrm{T}_{\text {lavg }}$ with contact time for TST case when a $50^{\circ} \mathrm{C}$ water jet impinges on a $350^{\circ} \mathrm{C}$ steel block. $\mathrm{U}_{\text {avg }}$ exceeds $\mathrm{W}_{\mathrm{cr}}$ within around $4 \mu \mathrm{s}$ and $\mathrm{T}_{\text {lavg }}$ reaches the homogeneous limit $\left(300^{\circ} \mathrm{C}\right)$ within $6.5 \mu \mathrm{s}$. Consequently, there is a high probability of homogeneous bubble nucleation after $6.5 \mu \mathrm{s}$ in this condition in this condition. For PST case, this time is observed as $4 \mu \mathrm{s}$.

Figure 8 shows the variation of average heat flux $q$ and maximum heat flux $\mathrm{q}_{\max }$ with time for both PST and TST cases. It indicates that the average heat flux at any time, $t$ never exceed the thermodynamic limit of the maximum heat flux $\mathrm{q}_{\max }$ for any boundary condition. This decision can assure the validity of the analytical investigation. 
Am. J. Applied Sci., 7 (6): 756-762, 2010

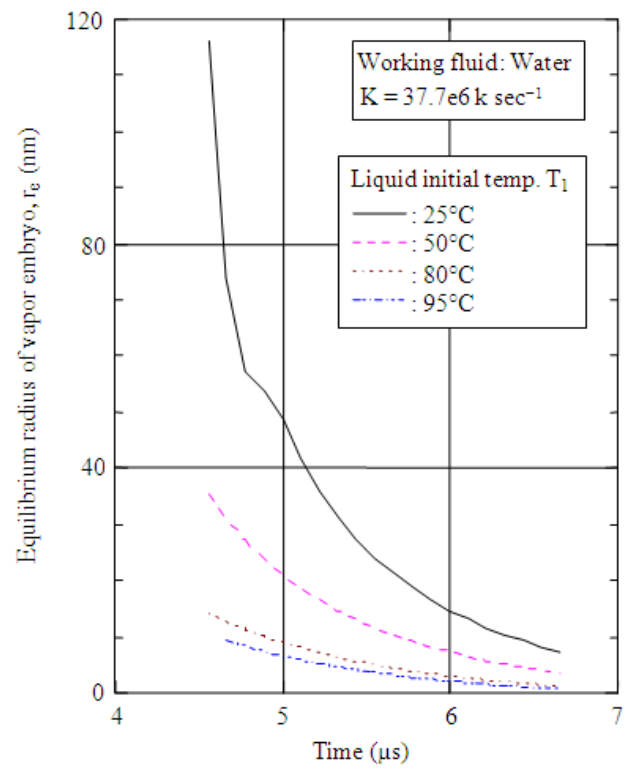

Fig. 6: Effect of initial jet temperature on equilibrium radius of vapor embryo for TST case

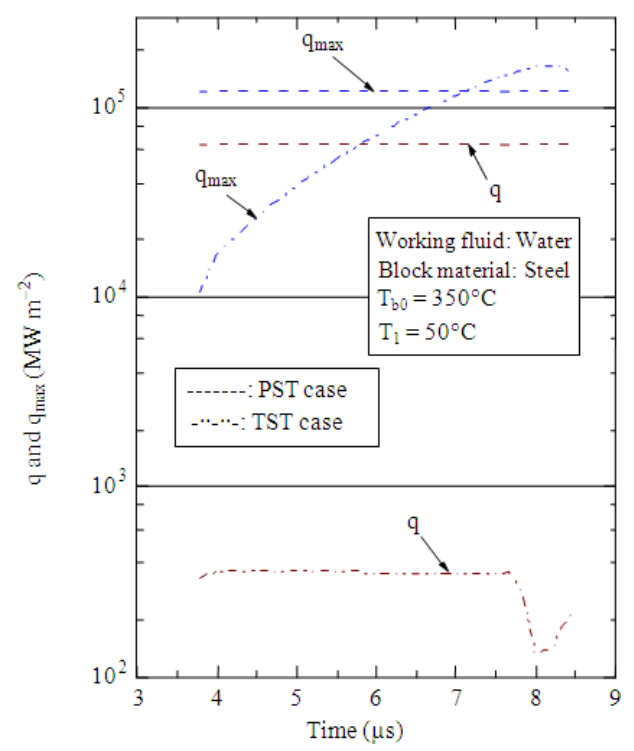

Fig. 7: Variation of minimum required energy to form a bubble and average liquid temperature for TST case

\section{DISCUSSION}

From the forgoing analysis, it is revealed that, during jet impingement quenching of hot surfaces near/above the thermodynamic limiting temperature, water stores enough energy for a contact period of 5$10 \mu$ s depending on the type of boundary conditions considered and there is strong possibility of nucleation.

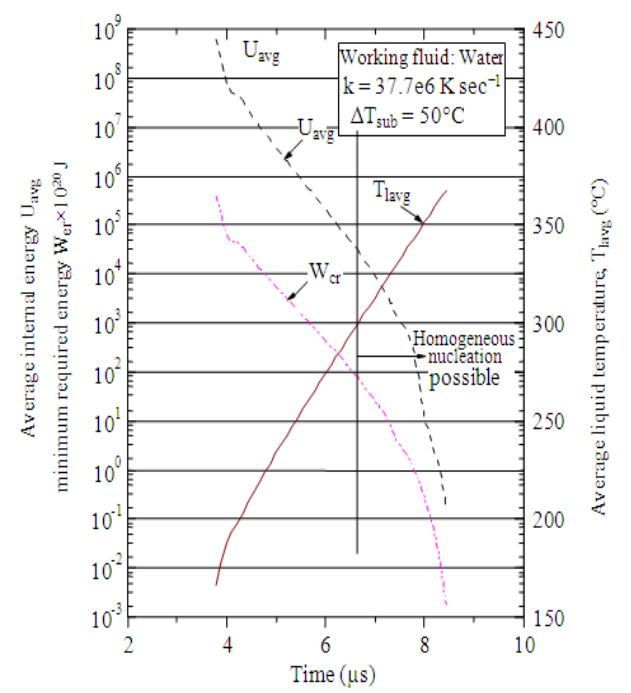

Fig. 8: Variation of average and maximum heat flux with time for different cases

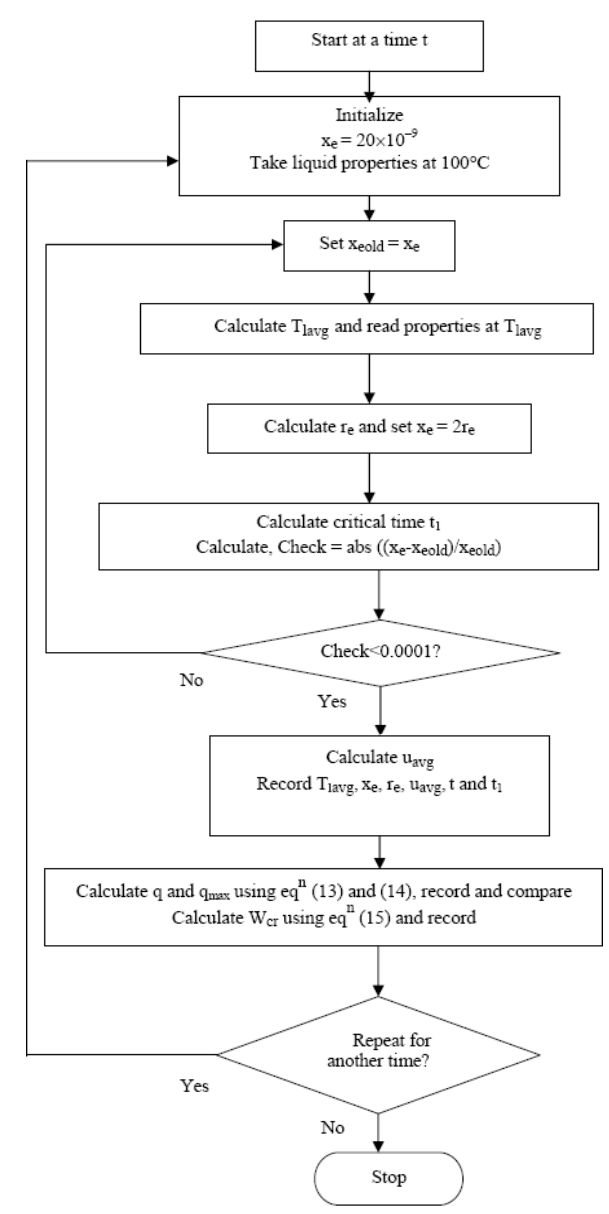

Fig. 9: Flow chart of the solution procedure 
As for example, it needs $4 \mu$ s of contact in PST case and $6.5 \mu \mathrm{s}$ of contact in TST case for the initiation of homogeneous bubble nucleation. Besides, as the average heat flux never exceeds the thermodynamic limit of maximum heat flux as well as the average internal energy of liquid well-exceeds the minimum energy required for bubble formation throughout the investigation, it is evident that, homogeneous bubble nucleation will initiate during jet impingement quenching after proper periods of contact.

\section{CONCLUSION}

The heat conduction method during jet impingement quenching is explored by the formation of a theoretical model of conduction heat transfer which gives some information on the possibility of homogeneous bubble nucleation. The model has been solved numerically where two different cases have been considered. The following observations can be devised from this study:

- A contact time of $4 \mu \mathrm{s}$ is required to trigger homogeneous bubble nucleation for the conditions where the impinging surface has a fixed temperature throughout the cooling process

- A contact time of $6.5 \mu \mathrm{s}$ is required to initiate homogeneous bubble nucleation for the conditions where the impinging surface temperature drops at a rate depending on time

- For both PST and TST cases, the average internal energy of the liquid exceeds the minimum energy necessary for bubble formation. Thus, when water is heated above the thermodynamic limit of superheat, there is always a chance of homogeneous nucleation

- Throughout the analytical investigation, for both the cases of PST and TST, the average heat flux, q never exceeds the thermodynamic limit of the maximum heat flux, $\mathrm{q}_{\max }$. This can conclude that the method of investigation, done in this study is valid and thus, there is indeed a possibility of homogeneous bubble nucleation during jet impingement quenching

- An accurate knowledge of the size of the vapor bubbles, number of molecules in a vapor bubble and the energy required to initiate bubble formation needs further investigation

\section{ACKNOWLEDGMENT}

This study is partly funded by CASR, BUET and partly by post graduate research grant by BUET. Authors gratefully acknowledge this.

\section{REFERENCES}

Carey, V.P., 1992. Liquid-Vapor Phase Change Phenomena. 2nd Edn., Hemisphere Publishing Corporations, ISBN: 13: 9781591690351, pp: 127-165.

Carslaw, H.S. and J.C. Jaeger, 2001. Conduction of Heat in Solids. 2nd Edn., Oxford University Press, ISBN: 13: 978-0198533689, pp: 50-64.

Hammad, J., M. Monde and Y. Mitsutake, 2004. Characteristics of heat transfer and wetting front during quenching by jet impingement. Therm. Sci. Eng., 12: 19-26.

Iida, Y., K. Okuyama and K. Sakuri, 1994. Boiling nucleation on a very small film heater subjected to extremely rapid heating. Int. J. Heat Mass Transfer, 37: 2771-2780.

Islam, M.A., P.L. Woodfield, A.K. Mozumder, Y. Mitsutake and M. Monde, 2006a. Boiling and wetting phenomena of hot surface during jet impingement quenching. Proceeding of the 13-IHTC, Sydney, Australia, pp: 1-12.

Islam, M.A., M. Monde, P.L. Woodfield and Y. Mitsutake, 2006b. Jet impingement quenching phenomena for hot surfaces well above the limiting temperature for solid-liquid contact. Int. J. Heat Mass Transfer, 51: 1226-1237.

Islam, M.A., M. Monde, P.L. Woodfield, Y. Mitsutake and A.K. Mozumder, 2007a. Jet impingement boiling in hot surfaces well above the limiting temperature for solid-liquid contact. Multiphase Sci. Tech., 19: 167-181.

Islam, M.A., M. Monde and P. Roy, 2007b. An analytical study of heat transfer during jet impingement quenching. Proceeding of the International Conference on Mechanical Engineering (ICME 07), Dec. 2007, Paper No. TH36.

Mozumder, A.K., M. Monde and P.L. Woodfield, 2005. Delay of wetting propagation during jet impingement quenching for a high temperature surface. Int. J. Heat Mass Transfer 48: 5395-5407.

Piggott, B.D.G., E.P. White and R.B. Duffey, 1976. Wetting delay due to film and transition boiling on hot surfaces. Nucl. Eng. Des., 36: 169-181.

Woodfield, P.L., M. Monde and A.K. Mozumder, 2005. Observations of high temperature impinging-jet phenomena. Int. J. Heat Mass Transfer, 48: 2032-2041.

Wolf, D.H., F.P. Incropera and R. Viskanta, 1993. Jet impingement boiling. Adv. Heat Trans., 23: 1-132. 